Sciendo

\title{
Can Minimalism Account for the Value of Truth?
}

\author{
Edward Moad \\ National University of Singapore
}

Disputatio Vol. 2, No. 24

May 2008

DOI: $10.2478 /$ disp-2008-0001

ISSN: 0873-626X 


\title{
Can minimalism account for the value of truth?
}

\author{
Edward Moad \\ National University of Singapore
}

\begin{abstract}
Michael Dummett, in 'Truth,' mounted an objection to the redundancy theory of truth on the grounds that it neglects to account for the normative features he claimed are part of the concept of truth. Paul Horwich, in 'The Minimalist Conception of Truth', notes that the same objection could be leveled against minimalism. He defends minimalism against Dummett's objection by offering a sketch of an instrumental account of the desirability of truth that is compatible with the minimalist thesis. In this paper, I will review Dummett's objection and Horwich's response, identifying some concerns with the account as it stands. I will modify the account to address those concerns, and so that it successfully explains the desirability of having all true beliefs in a way that is compatible with minimalism. I then mount an argument that truth is also intrinsically valuable. The question regarding the adequacy of the minimalist account of truth, then, hinges on whether the account is compatible with the fact of truth's intrinsic value, along with the question of whether that fact entails its also being essentially valuable.
\end{abstract}

The reason an objection to redundancy theory might be relevant for minimalism, is that they are both deflationary theories of truth. Deflationism, as a theory of truth, is the denial that truth is a substantive property. Deflationism rejects the view that a truth bearer's being true consists in its having some property that could be identified via an analysis of the concept of truth that goes any deeper than the 'truth schema': the belief (statement, proposition, etc.) that $\mathrm{p}$ is true iff $\mathrm{p}$. Accordingly, the schema alone exhaustively defines truth.

Redundancy theory, the earliest formulation of deflationism, basically took ' $p$ is true' to mean nothing more than ' $p$ '. But this raises the question of the function of the term 'truth'. If ' $p$ is true' means nothing more than 'p', then why do we use the term 'true' at all? Minimalism, in addressing this question, takes its cue from Quine's observation that the term truth has a 'disquotational' function. It allows us to generalize over truth-bearers (beliefs, statements,

Disputatio, Vol. II, No. 24, May 2008 
propositions, etc.) so as to affirm or deny 'some infinite lot of sentences' (Quine 1999: 146). For example, it allows us to say 'Everything he said was true,' instead of, 'if he said, 'Truth is not a substantive property,' then truth is not a substantive property; and if he said, 'Snow is white,' then snow is white...' and so on.

Minimalism adopts the disquotational view of the function of the term 'truth', and rejects the redundancy theorist's view that 'the statement that $\mathrm{p}$ is true' and 'p' are synonymous. That is, the biconditional in instances of the truth schema is understood as a material biconditional, thereby accommodating the fact that 'true' has a meaning over and above the meaning of 'p' (Horwich 1999: 242). Minimalism qualifies redundancy theory's strong implication that truth is not a property at all by holding that truth is not a substantive property. Truth is a property inasmuch as it plays the inferential role of a logical predicate. For example, it allows us to infer, from 'what she said is true' and 'she said it is raining', to 'the statement that it is raining is true' and 'it is raining'. Minimalism holds that the fact that constitutes the meaning of truth is just our tendency to make inferences of this kind. The concept of truth is exhaustively explained as our disposition to accept all instances of the truth schema (Horwich 1999: 243-245).

\section{Dummet's objection and Horwich's response}

Dummett asks us to compare truth and falsity with the concepts of winning and losing a game. For any game, we can give a description of all the possible winning scenarios on the one hand, and all the losing scenarios on the other. For chess, one could give a description of every possible checkmate position. For football, one could give a description of the possible final scores, as well as the series of plays on each side correlated to those scores. For arm-wrestling, one could offer the simple description of pushing the opponent's arm back on the table. For each game, descriptions of the winning scenarios are quite different, depending on the rules of the game. By themselves, they do not inform us as to what it is in virtue of which the scenarios they describe are all called 'winning'. Thus, the descriptions themselves would not bestow an understanding of the concept of winning on someone who did not already grasp it. This is because it is part of the very concept of winning that it is a desirable outcome, and this 
desirability is not included in the mere descriptions of the winning scenarios for each game (Dummett 1959: 142, 149).

'Likewise,' writes Dummett, 'It is part of the concept of truth that we aim at making true statements' (Dummett 1959: 143). If this is so, then the deflationist theory does not explain the concept of truth any better than descriptions of the winning scenarios for every game would explain the concept of winning. The truth schema gives the conditions under which a given truth bearer will be true, but leaves out the essential fact that meeting such conditions is, in each case, desirable.

Horwich's response to the Dummett objection is to reject the idea that the desirability of truth is part of the concept of truth. 'In response, however, it can be said that in order for an account of truth to be adequate, it suffices that it be able to explain the desirability of truth - it is not required that the desirability of truth be an integral part of the account' (Horwich 1999: 256). Between Dummett and Horwich, the fact that truth is desirable is not under dispute. The question is only whether the desirability of truth is conceptually separable from truth itself. If not, minimalism will be inadequate as an account of truth. If so, an account of the desirability of truth should be available that is not integral to the concept of truth, and thus compatible with the minimalist position.

Horwich's account is, specifically, one of the desirability of having all true beliefs. The basic idea is to derive the value of a belief's being true from the practical advantage it would confer in bringing about desirable states of affairs. I take the liberty of breaking it down in the following manner for ease of analysis.

1) If there is a state of affairs, $G$, that I desire, and a possible action, $A$, that is under my control and that I believe will bring about $G$, then the content of that belief will be a 'directly action-guiding proposition' $D$ : 'If I do $A$, then I will get $G$ '.

2) If I desire $G$, then I will desire that if I believe $D$, then $D$.

3) I desire $G$.

4) I desire that if I believe $D$, then $D(2,3)$.

5) The disquotational function of truth allows us to reformulate 4) as: 'I desire that if I believe that $D$, then that $D$ is true.'

6) Reformulated, premise 4) has the logical form, 'I desire that if I believe $x$, then $x$ is true'.

7) I desire that all my directly action-guiding beliefs are true $(4,5,6)$. 
8) Directly action-guiding beliefs are derived from other beliefs by means of truth-preserving inferences.

9) Any one of my beliefs might be a premise in some truth-preserving inference to a directly action-guiding belief.

Conclusion: I desire that all my beliefs be true (7,9) (Horwich 1999: 256-7).

\section{A modification to Horwich's account}

The inference to the conclusion from premises 7 and 9, above, would imply that the mere possibility that a given belief might be a premise in some truth-preserving inference to a directly action-guiding belief is, alone, enough to explain the desirability of that belief's being true. Consequently, the mere possibility of having a given desire is enough to underwrite the desirability of the truth of any beliefs that would serve as premises in inferences that would guide in fulfilling that desire. But it is possible for almost anything to be a means to some possible end. If practical reason worked this way, we would desire everything besides that which cannot possibly be a means to any possible end. This implication is absurd. Any explanation of the desirability of something on the basis of its being instrumental in the realization of some desirable end must proceed on the basis of the actual desiring of the end, not merely the possibility of its being desired.

Thus, unless all my beliefs actually are premises in valid inferences to directly action-guiding beliefs, the desirability of having all true beliefs cannot be explained in these terms. In order to support the conclusion in Horwich's account, premise 9 would have to be reformulated to assert that every one of my beliefs actually is a premise in a valid inference to a directly action-guiding belief. Furthermore, in saying that I desire that all my beliefs be true, I am not only saying that I desire that all the beliefs I actually have are true. I am also saying that I desire that any belief I may form in the future be true. Therefore, premise 9 should be reformulated as:

9)*Every possible belief is a premise in a truth-preserving inference to a directly action-guiding belief.

This is a strong claim. Consider, however, the desire to be optimally prepared to bring about any state of affairs you might possibly desire. The explanation of the value of having all true beliefs would then be 
that it is a condition of being optimally prepared to fulfil any desire that one might possibly have. If being optimally prepared to fulfil any desire that one might possibly have is understood as a state of affairs that is actually desired (not merely one that it is possible to desire), it would be sufficient to underwrite the desirability of having all true beliefs — as a component of the directly action-guiding belief drawn from the following inference.

1) I will be optimally prepared to fulfil any desire that I might have only if all my beliefs are true.

2) All my beliefs will be true if and only if, for any proposition $x$, I believe $x$ only if $x$.

3) I will be optimally prepared to fulfil any desire that I might have only if, for every proposition $x$, I believe $x$ only if $x(1,2)$.

4) Let $p$ be the content of any proposition describing a state of affairs that obtains.

Conclusion: I will be optimally prepared to fulfil any desire that I might have only if I believe that $p .(3,4)$.

Any possible belief can play the part of premise 4 in this inference. Moreover, the conclusion here is a directly action-guiding belief involving a state of affairs the desirability of which can explain, instrumentally, the value of having all true beliefs. With this refinement, then, Horwich's account would explain the value of truth as derivative on that of some other desirable state of affairs, so long as that state of affairs is that of being optimally prepared to fulfil any desire that one might have.

But this arrangement gives rise to a concern. Horwich and Dummett are in apparent agreement that having true beliefs is desirable in a general sense. In Dummett's case, the desirability of having all true beliefs is pervasive enough for him to consider that it is part of the very concept of truth. It would be fair to consider Horwich to be attempting an account of the desirability of having true beliefs that would explain that degree of pervasiveness. Consequently, the state of affairs the desirability of which is to underwrite the desirability of having true beliefs need not only be one that is plausibly conditional, in a directly action-guiding belief, on having all true beliefs. It needs to be a state of affairs the desirability of which is as pervasive as the desirability of having true beliefs appears to be. If we presuppose, with Dummett and Horwich (as we have good reason to) that the 
desirability of having all true beliefs is universal, then being optimally capable of fulfilling one's desires should also be universally desirable.

The best case that can be made that being so optimally capable is universally desirable is, perhaps, to observe that desiring to be able to fulfil one's desires seems to follow on desiring anything at all. Likewise, desiring to be capable of doing something follows on desiring to do that thing. Thus, inasmuch as anything is desirable, being optimally capable of fulfilling one's desires is also desirable.

An objection could be made here that one could have a desire that one is glad of being incapable of fulfilling, for example, eating a fattening dessert. But this is best understood as a case of conflicting desires; that is, the desire for dessert against the desire to lose weight. The desire to lose weight may give rise to a desire to be incapable of fulfilling the conflicting desire to eat, but it probably also gives rise to a desire to be capable of refraining from eating even if dessert is available. As long as there is a conflicting desire to eat (which is what, in this case, makes the example intelligible as an instance of desiring to be incapable of fulfilling a desire), it seems inconceivable that there not be a desire, albeit one in conflict, for the capability of eating dessert. The life of our appetites is a complex one, and the conflicts that ensue therein frequently manifest conflicting desires regarding our capabilities of fulfilling conflicting desires. However, this seems no reason not to suppose that desiring anything does not come attached with the desire of being capable of fulfilling one's desires, however conflicting they might be.

\section{Wishing rings and true beliefs}

Even if the preceding account successfully identifies sufficient conditions of the desirability of having true beliefs that are compatible with minimalism, it does not preclude the possibility that such conditions are not necessary for its desirability, and that having true beliefs is desirable for additional reasons that are incompatible with minimalism. That is, truth may be essentially desirable, as Dummett contends, as well as extrinsically desirable for the reasons just suggested. In order to determine whether this is the case, we must somehow consider whether truth would have any value divorced from these practical advantages. 
To this end, one might imagine a wishing ring that automatically brings about any state of affairs that one desires. In doing so, it fulfils all the necessary and sufficient conditions for being optimally capable of fulfilling any desire that one might have. In such circumstances, having all true beliefs would no longer be a condition for being so capable. If the desirability of having all true beliefs is exhaustively explained in terms of its being a means of realizing that state of affairs, then the wishing ring should effectively eliminate any concern for the truth of one's beliefs. It is left, then, to ask if, in possession of the wishing ring, one would cease to be interested in having true beliefs.

At the risk of appearing to appeal to philosophical romanticism, I suggest that no philosopher should answer this in the affirmative. On the contrary, once in possession of such a ring, she would have all true beliefs. Consequently, she would believe that her having all true beliefs is an intrinsically desirable state of affairs; one, of course, that the wishing ring will have brought about. Perhaps this begs the question. But if so, the question begged is just that of whether our concern for the truth of our beliefs regarding, for example, the truth or falsehood of minimalism is not based solely on the fact that having true beliefs about the issue confers some practical advantage in bringing about some desired end other than that of having true beliefs. It is then left to the reader to determine just what such end she thinks having true beliefs about minimalism will bring about. Otherwise, one must conclude that one desires having true beliefs for its own sake.

Consider where the analogy Dummett makes from truth to winning breaks down. Imagine we change the rules of chess so that the object of the game is to get yourself into checkmate, rather than to checkmate your opponent. Is it, then, the case that, in 'suicide chess', the object of the game is to lose, or is it just that, in 'suicide chess', getting into checkmate is the state of affairs that constitutes 'winning'? The answer is clearly the latter. Thus, 'winning' just is bringing about the desired state of affairs, as determined by the rules of the game.

Children sometimes play 'opposite day', where they try to communicate by always saying the opposite of what they mean. Imagine a 'falsehood day', where we try to always express only false propositions. On 'falsehood day', will all the falsehoods be truths, in virtue of their being that which we aim to express? Of course not. This is because, unlike winning, expressing the true proposition involves more than having brought about the desired state of affairs. It involves the proposition's being true, which is more than its being the one we 
aim to express. The break in the analogy is interesting in itself, but our purpose in considering it is arrived by remembering that it is not the value of expressing true propositions that is in question, but the value of having all true beliefs.

That our emphasis is more properly laid on the latter is evident if we consider the relation between the two. Dummett claimed that it is part of the concept of truth that we aim at making true statements. But wherein might lie the value of making a true statement, without believing it? All the imaginable scenarios in which making a true statement one does not believe is valuable, are ones in which its value is merely extrinsic. You might be on a quiz show where giving the right answer to a question about which you are completely ignorant, and thus have no beliefs, will win you money. Or, you might express of number of different hypotheses to a group of students regarding a question over which you have not yet formed any beliefs, in hopes that, in the process, someone will form true beliefs on the topic. In this case, the value of expressing true propositions is parasitic on the value of having true beliefs. But the value of latter is of a different nature.

Imagine changing 'falsehood day' to 'false belief day'. On 'false belief day', we aim to have false beliefs, not just to make false statements. This game would prove a bit more challenging. To believe that $p$ is to believe that $p$ is true. To aim to believe only what is false, then, is to aim to believe to be true only what one believes is false. The root of this conundrum lies, I suggest, in the fact that belief is essentially aimed at truth; to believe is necessarily to want to have true beliefs.

In anticipation of the obvious counter-examples, we should note that there is a subtle distinction between having a belief that one wants to be false, and wanting to have a false belief. For example, when a parent 'does not want to believe' that their child is addicted to drugs, it is a case of their not wanting their child to be a junkie; not one of their wanting to have false beliefs. Their wanting to believe their child is not a junkie is a matter of their wanting the state of affairs to be such that such a belief is true. Otherwise, we should conclude that the parent wants the child to be a junkie, so that their belief to the contrary would be false. Clearly, this is not what is meant by the expression. The only plausible examples of 'wanting to have a false belief' are of just these sorts. We believe what we take to be true, and to form beliefs is to sort what appears to be true from what appears to be false, understanding the world in terms of the 
former rather than the latter. The process presupposes having true beliefs as the aim. To believe is to want true beliefs.

Returning to the wishing ring scenario, we arrive at the following conclusion. If, indeed, the value of having true beliefs is solely extrinsic, following on the desire of being optimally capable of satisfying one's desires, then having such a ring would not only eliminate any concern one might have for the truth of their beliefs. It would render them without beliefs altogether, because in removing the condition under which, alone, having truth is desirable, it will have thereby eliminated an essential feature of believing. This fact, I contend, strengthens the case that having all true beliefs is intrinsically desirable.

The question, then, is whether the intrinsic value of truth is compatible with minimalism. This hinges, in part, on whether truth's being intrinsically valuable entails it's being essentially valuable. If truth is essentially valuable, then any account of truth which does not include the normative feature, such as minimalism, is incomplete. On the other hand, if truth has intrinsic value contingently, then a complete account of what truth is need not incorporate the normative features. The issue, then, turns on the questions: 1) whether every intrinsic property is an essential property, 2) whether intrinsic value is always essential value, and more specifically, 3) how these questions stand with regard to the properties and/or value inherent in truth.

$$
\begin{array}{r}
\text { Edward Moad } \\
\text { Department of Philosophy } \\
\text { National University of Singapore } \\
3 \text { Arts Link, Singapore 117570, Singapore } \\
\text { phimer@nus.edu.sg }
\end{array}
$$

References

Dummett, Michael. 1959. Truth. Proceedings of the Aristotelian Society. 59: 141-162.

Horwich, Paul. 1999. The Minimalist Conception of Truth. In Blackburn and Simmons (ed.), Truth (pp. 239-263). Oxford: Oxford University Press.

Quine, W.V. 1999. Philosophy of Logic. In Blackburn and Simmons (ed.), Truth (pp. 144-146). Oxford: Oxford University Press. 